Provided for non-commercial research and education use. Not for reproduction, distribution or commercial use.

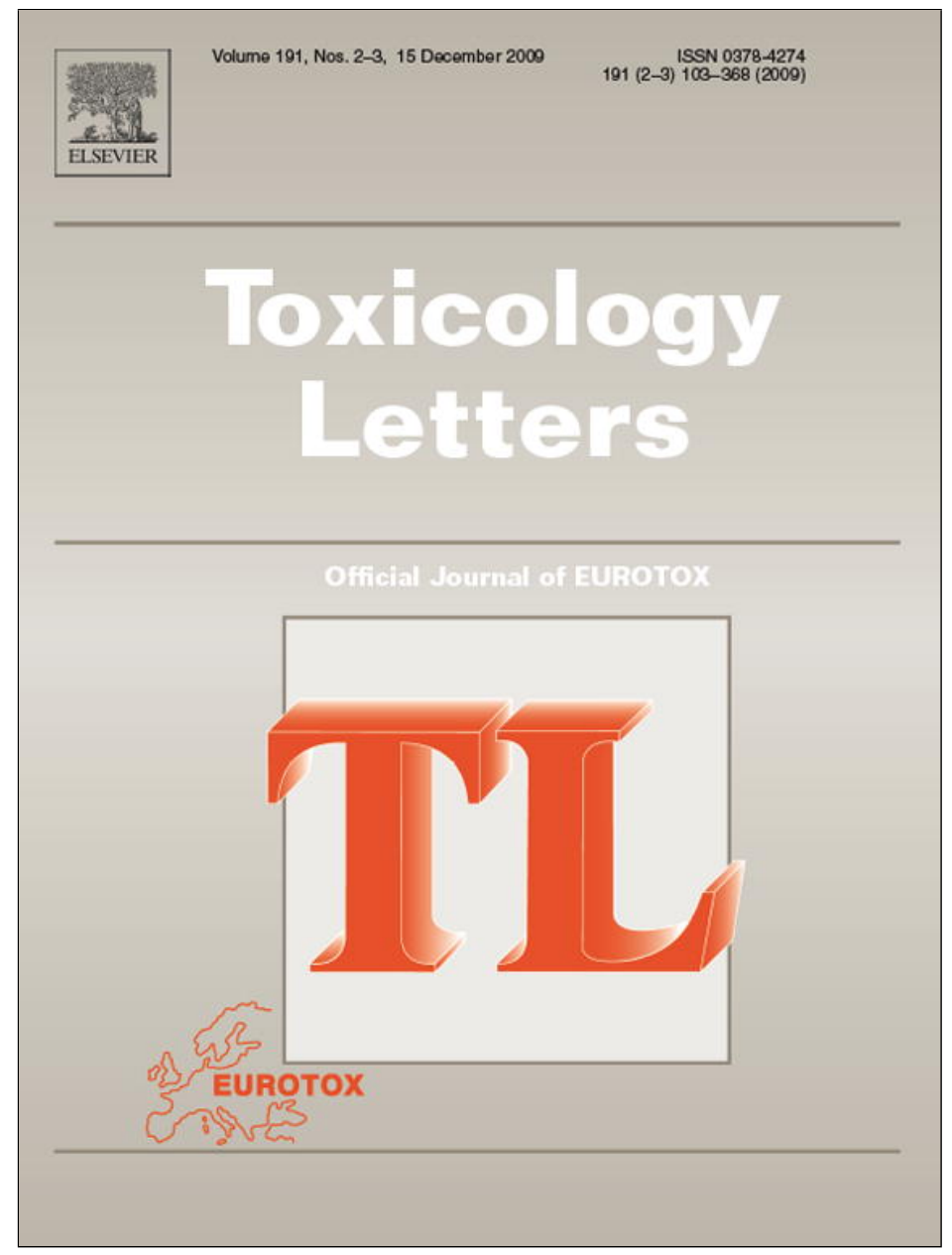

This article appeared in a journal published by Elsevier. The attached copy is furnished to the author for internal non-commercial research and education use, including for instruction at the authors institution and sharing with colleagues.

Other uses, including reproduction and distribution, or selling or licensing copies, or posting to personal, institutional or third party websites are prohibited.

In most cases authors are permitted to post their version of the article (e.g. in Word or Tex form) to their personal website or institutional repository. Authors requiring further information regarding Elsevier's archiving and manuscript policies are encouraged to visit:

http://www.elsevier.com/copyright 


\title{
Effects of TCDD on Spermatogenesis Related Factor-2 (SRF-2): Gene expression in Xenopus
}

\author{
Federica Rossi ${ }^{a}$, Giovanni Bernardini ${ }^{a, c}$, Patrizia Bonfanti ${ }^{b}$, \\ Anita Colombo ${ }^{b}$, Mariangela Prati ${ }^{a}$, Rosalba Gornati ${ }^{\mathrm{a}, *}$ \\ a Dipartimento di Biotecnologie e Scienze Molecolari, Università dell'Insubria, V.J.H. Dunant 3, 21100 Varese, Italy \\ ${ }^{\mathrm{b}}$ Dipartimento di Scienze dell'Ambiente e del Territorio, Università di Milano Bicocca, P.zza della Scienza 1, 20126 Milano, Italy \\ c Centro di Ricerca Interuniversitario Politecnico di Milano e Università dell'Insubria "The Protein Factory", Italy
}

\section{A R T I C L E I N F O}

\section{Article history:}

Received 27 July 2009

Accepted 29 August 2009

Available online 6 September 2009

\section{Keywords:}

TCDD

SRF-2 gene

Real-time PCR

Xenopus laevis

Toxicity

\begin{abstract}
A B S T R A C T
2,3,7,8-Tetra-chlorodibenzo-p-dioxin (TCDD) is one of the most toxic dioxins belonging to the wide family of Endocrine Disruptors (EDs), environmental chemicals that adversely interfere with endocrine processes and upset normal function of some target systems. It has been hypothesized that EDs enter cellular cytosol, bind to the Aryl Hydrocarbon Receptor (AhR) and form a heterodimer with the AhR nuclear translocator; this complex binds xenobiotic responsive elements that drive activation of the socalled "Ah gene battery". Spermatogenesis Related Factor-2 (SRF-2) is one of the most recently cloned genes involved in germ cell division and differentiation, whose expression seems to be affected by treatment with TCDD. With the aim to try to clarify the underlying mechanism of TCDD and to investigate if SRF-2 gene represents a good biomarker for ED exposure, we used Xenopus laevis as an animal model, considered to be almost insensitive toward TCDD effects. In this study we reported the partial cloning of SRF-2 cDNA in X. laevis; we then evaluated the SRF-2 expression in embryos exposed to TCDD $0.62 \mu \mathrm{M}$ by real-time PCR. We also analyzed SRF-2 expression in several adult control tissues and in testis after perilymphatic injection of a single dose of $10 \mu \mathrm{g} / \mathrm{kg}$ body weight. Although SRF-2 expression does not seem to be affected by the treatment, exposed embryos died within 15 days. In the light of these results, we can conclude that SRF-2 is not a good candidate in signalling EDs exposure and that the molecular mechanism for TCDD toxicity in Xenopus likely involves the AhR signalling cascade, as in other vertebrate species.
\end{abstract}

(c) 2009 Elsevier Ireland Ltd. All rights reserved.

\section{Introduction}

Controlled stage-specific gene expression is required to precisely regulate germ cell differentiation, and it is essential to evaluate for those genes related to the endocrine system. It is obvious that the effects of exposure to compounds that could interfere with the expression of these genes must be studied and controlled, as this can have detrimental effects on reproductive and developmental processes. Endocrine Disruptors (EDs) are environmental chemicals that adversely affect endocrine processes and upset normal function in some target systems, such as the reproductive organs, and during developmental stages (Sikka and Wang, 2008). Among the innumerable natural and synthetic EDs, there are natural hormones from animal and human waste, breakdown products of surfactants found in soaps and detergents, as well as heavy metals, plastics, and cosmetics (Choi and Jeung, 2003).

\footnotetext{
* Corresponding author. Tel.: +39 0332421444; fax: +39 0332421500

E-mail address: rosalba.gornati@uninsubria.it (R. Gornati).
}

Most EDs are ubiquitous and persistent environmental pollutants, that bioaccumulate in both humans and animals because of their lipophilicity (Zook and Rappe, 1994). According to one hypothesized mechanism, EDs enter the cellular cytosol, bind the AhR and form an heterodimer with the AhR nuclear translocator; this complex binds xenobiotic responsive elements driving activation of the so-called “Ah gene battery" (Pollenz et al., 1994; Nebert et al., 2000; Matsumura, 2003; Schultz et al., 2003).

Spermatogenesis Related Factor-2 (SRF-2) is one of the most recently cloned genes involved in germ cell division and differentiation (Yamano et al., 2005). Literature data report that in rat, SRF-2 expression seems to be downregulated by treatment with $2,3,7,8$ tetra-chlorodibenzo-p-dioxin (TCDD), one of the most toxic dioxins belonging to the wide family of EDs (Birnbaum and De Vito, 1995). For this reason it has been proposed as a biomarker for exposure to EDs.

Although most genes are up regulated by TCDD treatment via the AhR signalling cascade, the mechanism that downregulates the expression of SRF-2 has not yet been clarified (Yamano et al., 2005).

To verify if this gene could be used as a biomarker for EDs and to provide further insight into the mode of action of TCDD, we 
used a non-mammalian species, the amphibian Xenopus laevis, as an animal model. It is considered to be almost insensitive to TCDD as the binding affinity of its two AhR isoforms is at least 20-fold lower than that of mouse AhR (Lavine et al., 2005; Elskus, 2005). For a long time CYP1A induction has been utilized to evaluate the functional capability of expressed AhR. Earlier, we demonstrated that the induction of CYP1A occurs in adult X. laevis, as well as in embryos, already at stage 35 (2 days post-fertilization), in response to aryl hydrocarbon receptor agonists (TCDD, 3-methylcholantrene and benzo(a)pyrene) (Colombo et al., 1996, 2003; Dell'Orto et al., 1998). Ohi et al. (2003) demonstrated that Xenopus AhR gene is expressed during early development in parallel with the expression of the CYP1A gene, which is thought to be regulated by AhR.

Therefore, even if $X$. laevis is scarcely sensitive towards several pollutants, the CYP1A upregulation following the exposure to AhR agonists demonstrates that AhR is functional.

In this paper, we report the partial cloning of SRF-2 of X. laevis. We then evaluated the developmental toxicity following acute (5 days) and chronic ( 15 days) exposure to TCDD starting from late blastula stage, and by real-time PCR (RT-PCR), the SRF-2 expression in Xenopus embryos exposed to $0.62 \mu \mathrm{M}$ TCDD. SRF-2 expression was also analyzed in several adult normal tissues and in testis after perilymphatic injection of a TCDD single dose of $10 \mu \mathrm{g} / \mathrm{kg}$ body weight.

\section{Materials and methods}

\subsection{In vitro fertilization and embryo treatment}

X. laevis, purchased from the Centre d'élevage de Xénopes du CNRS (Rennes, France), were maintained in aquaria (Tecniplast, Varese, Italy). Three adult females per experiment (experiment $n=3$ ) were injected with 700-800 I.U. of human chorionic gonadotropin in the evening. About $16 \mathrm{~h}$ later, females were made to lay eggs in $90 \mathrm{~mm}$ plastic Petri dishes. Eggs were immediately inseminated with sperm suspension; after $1 \mathrm{~min}, 30 \mathrm{ml}$ of FETAX solution were added to each Petri dish (FETAX solution composition in $\mathrm{mM}$ was: $\mathrm{NaCl} 10.69, \mathrm{NaHCO}_{3} 1.14, \mathrm{KCl} 0.4, \mathrm{CaCl}_{2} 0.1$ $\mathrm{CaSO}_{4} \cdot 2 \mathrm{H}_{2} \mathrm{O} 0.35$ and $\mathrm{MgSO}_{4}$ 0.62). Xenopus sperm suspension was obtained by mincing the testes in cold De Boer-TRIS solution (DBT solution composition in $\mathrm{mM}$ was: $\mathrm{NaCl} 119, \mathrm{KCl} 2.5, \mathrm{CaCl}_{2} 1.8, \mathrm{TRIS} / \mathrm{HCl} 10$ ). The osmolarity in DBT solution was higher than FETAX solution preventing spermatozoa from initiating flagellar movement (Bernardini et al., 1988). Successful insemination was detected when after a few minutes all the eggs were oriented with the dark side (animal pole) up. The 'bad' eggs, the unfertilized ones and any embryos with abnormalities, were eliminated. Viable embryos were placed in plastic Petri dishes and maintained at $23^{\circ} \mathrm{C}$ until the end of the assay.

The 2,3,7,8-tetrachlorodibenzo-p-dioxin (99.1\% pure, AccuStandard Inc., New Haves, USA) was dissolved in dimethylsulfoxide (DMSO) at a concentration of $248 \mu \mathrm{M}$ (stock solution), then diluted with FETAX solution in order to obtain a range of concentrations between $0.125 \mu \mathrm{M}$ and $0.62 \mu \mathrm{M}$. At the highest TCDD concentration, the final quantity of DMSO was $0.25 \%$. At least two replicates of ten dejelled normal blastula (stage 10, Nieuwkoop and Faber, 1994) from the same female were put in $40 \mathrm{~mm}$ Petri dishes in FETAX solution, in FETAX and DMSO, and in FETAX, DMSO and TCDD.

Each day the solution was renewed and the dead embryos removed. At day 5 p.f. the number of dead embryos was calculated and the surviving embryos were anesthetized by immersion in 3-aminobenzoic acid ethyl ester (MS-222, Sigma Milan, Italy) and then fixed with formaldehyde. The number of malformed larvae was recorded and the head-tail length of individual normal embryos was measured.

Moreover, a 15-day TCDD treatment was carried out in order to study the TCDD effects on more advanced stages of Xenopus development and to obtain larvae for subsequent molecular analysis.

In this test 900 embryos at blastula stage were divided into 3 groups: the first group was exposed to TCDD $0.62 \mu \mathrm{M}$ for the entire period (15 days); the second group was exposed to TCDD $0.62 \mu \mathrm{M}$ only during the first 5 days of the test and then placed in FETAX solution for the remaining 10 days (Recovery); and the third was kept in FETAX solution throughout the test. During the entire test, solutions were renewed daily and the number of dead embryos recorded. Two pools of 50 embryos for each experimental group were collected at the fifth, tenth, and fifteenth day, frozen in liquid nitrogen and stored at $-80^{\circ} \mathrm{C}$ until molecular biology analysis.

\subsection{Adult treatments}

Sexually mature Xenopus males weighing $32 \pm 4.5 \mathrm{~g}(n=6)$ were divided into 2 groups of three animals for TCDD treatment and as a control. The treated group received a single injection of TCDD $(10 \mu \mathrm{g} / \mathrm{kg}$ body weight) into the lymphatic sac as a suspension in DMSO and corn oil $(1: 50, \mathrm{v} / \mathrm{v})$. The control group received a single injection of the vehicle. After $45 \mathrm{~h}$ the animals were sacrificed; testis and liver were removed, and immediately frozen in liquid nitrogen and kept at $-80^{\circ} \mathrm{C}$ until RNA extraction.

\subsection{RNA extraction and retrotranscription}

RNA was extracted from about 20 embryos or $50 \mathrm{mg}$ of tissues with $0.5 \mathrm{ml}$ TRIzol Reagent (Invitrogen, Carlsbad, CA, USA) to recover the total RNA, which was subsequently treated with DNAse (DNA free, Ambion, Austin, TX, USA) following the manufacturer's instructions.

About $2 \mu \mathrm{g}$ total RNA were retrotranscribed using Moloney Murine Leukemia Virus (M-MLV) reverse transcriptase (Invitrogen, Carlsbad, CA, USA). Briefly, RNA was added to a mix containing $50 \mathrm{pmol}$ random primers, $1 \mu \mathrm{l}$ dNTPs mixture $(10 \mathrm{mM})$, and water to a final volume of $12 \mu \mathrm{l}$. The mix was heated at $65^{\circ} \mathrm{C}$ for $5 \mathrm{~min}$ and chilled on ice. Then, $4 \mu \mathrm{l} 5 \times$ retrotranscription buffer, $2 \mu \mathrm{l} 0.1 \mathrm{M}$ DTT, $40 \mathrm{U}$ RNaseOUT, and $200 \mathrm{U}$ M-MLV retrotranscriptase were added to a final volume of $20 \mu \mathrm{l}$. After incubation at $37^{\circ} \mathrm{C}$ for $50 \mathrm{~min}$, the reaction was stopped at $70^{\circ} \mathrm{C}$ for $15 \mathrm{~min}$. The obtained cDNA was diluted $1: 5$ with water and stored at $-20^{\circ} \mathrm{C}$.

\subsection{Cloning of SRF-2 CDNA}

For the cloning procedure, $5 \mu \mathrm{l}$ of ovary cDNA was amplified using $25 \mathrm{pmol}$ of SRF-up_Nov and SRF_low_Nov, $5 \mu$ l of $5 \times$ buffer, $5 \mathrm{nmol}$ of dNTP mix and $1 \mathrm{U}$ Taq DNA polymerase (Promega, Madison, WI, USA) and water to a final volume of $50 \mu \mathrm{l}$. Reaction mixtures were subjected to 28 cycles, using the following parameters: denaturation at $94^{\circ} \mathrm{C}$ for $30 \mathrm{~s}, 8$ cycles touch down from $53^{\circ} \mathrm{C}$ to $49^{\circ} \mathrm{C}$, and 27 cycles at an annealing temperature of $49^{\circ} \mathrm{C}$ and elongation at $72^{\circ} \mathrm{C}$ for $1 \mathrm{~min}$. The products thus obtained were cloned into pGEM-T Easy cloning vector (Promega, Madison, WI, USA) and sequenced (M.Medical, Milan, Italy).

\subsection{Rapid amplification of CDNA ends (3'- and $\left.5^{\prime}-R A C E\right)$}

The 3'-RACE was performed using a 3'-RACE system kit (Invitrogen, Carlsbad, CA, USA) according to the manufacturer's instructions. Briefly, the first-strand cDNA was synthesized starting from $1 \mu \mathrm{g}$ to $5 \mu \mathrm{g}$ of total RNA using the primer RACE_AP; $2 \mu \mathrm{l}$ of this cDNA was then amplified using 25 pmol of RACE_AUAP and SRF_3RACE. The thermocycler was set as follows: $94^{\circ} \mathrm{C} 3$ min then 30 cycles at $94{ }^{\circ} \mathrm{C} 30 \mathrm{~s}, 55^{\circ} \mathrm{C}$ $30 \mathrm{~s}$, and $72{ }^{\circ} \mathrm{C} 30 \mathrm{~s}$, and a final elongation at $72^{\circ} \mathrm{C}$ for $4 \mathrm{~min}$. The resulting products were run on a $1 \%$ agarose gel, purified, cloned into the pGEM-T easy vector, and sequenced.

The 5'-RACE was performed according to the method published by SempleRowland et al. (1999) with slight modifications. Briefly, $4 \mu \mathrm{g}$ total RNA, extracted from $X$. laevis ovary, was reversed transcribed using $200 \mathrm{U}$ M-MLV reverse transcriptase (Invitrogen) following the manufacturer's instructions and using $20 \mathrm{pmol}$ of sequence-specific antisense primer SRF_5RACE1. The reaction was incubated at $42^{\circ} \mathrm{C}$ for $50 \mathrm{~min}$ and stopped by placing the tube on ice; excess primers, dNTPs and buffer were removed using a Wizard SV Gel and PCR Clean-Up System (Promega, Madison, WI, USA). In the final step of the procedure, the DNA was eluted in $30 \mu$ l water. A poly dCTP tail was added to the single-stranded cDNA present using terminal deoxynucleotidyl transferase (Promega, Madison, WI, USA). The mixture was denaturated at $94^{\circ} \mathrm{C}$ for $3 \mathrm{~min}$, chilled on ice, incubated at $37^{\circ} \mathrm{C}$ for $10 \mathrm{~min}$ and stopped at $70^{\circ} \mathrm{C}$ for $10 \mathrm{~min}$; the excess of dCTP and buffer was removed as described above. Second-strand cDNA synthesis was carried out using $5 \mathrm{U}$ Taq Polymerase (Qiagen, Milan, Italy), $0.2 \mu \mathrm{M}$ of a poly d(G) anchor primer (RACE_AAP), $200 \mu \mathrm{M}$ dNTP mix and $10 \times$ PCR buffer. The reaction was incubated in a thermal cycler at the following conditions: $40^{\circ} \mathrm{C}$ for $5 \mathrm{~min}, 72^{\circ} \mathrm{C}$ for $2 \mathrm{~min}$. Then the temperature was increased to $80^{\circ} \mathrm{C}$. At this point $0.2 \mu \mathrm{M}$ of the nested sequence-specific primer SRF_5RACE2 and a nested anchor primer RACE_AUAP were added for the amplification step at the following conditions: $94^{\circ} \mathrm{C}$ for $1 \mathrm{~min}, 54^{\circ} \mathrm{C}$ for $1 \mathrm{~min}, 72^{\circ} \mathrm{C}$ for $1 \mathrm{~min}$ ( 30 cycles), and the last extension time $72^{\circ} \mathrm{C}$ for $10 \mathrm{~min}$ and then kept at $4{ }^{\circ} \mathrm{C}$. Subsequently, $1 \mu \mathrm{l}$ of a 1:10 dilution of the PCR products was reamplified using the nested anchor prime RACE_AUAP and the nested sequence-specific primer SRF_5RACE3. The thermocycler was set as reported above. The resulting products were run on a $1 \%$ agarose gel, purified, cloned into the pGEM-T easy vector and sequenced.

\subsection{Quantitative and semi-quantitative RT-PCR}

$5 \mu \mathrm{l}$ of cDNA were added to $12.5 \mathrm{ml}$ RealMaster Mix/SYBR solution (RealMaster Mix kit, Applied Biosystem, Monza, Italy), 0.2 pmol of RT-SRF_up, RT_SRF_low, RT-GAPDH_up, RT-GAPDH_low, and water to a final volume of $25 \mu \mathrm{l}$. Glyceraldehyde-3-phosphate dehydrogenase was used as the reference gene. Realtime PCR was performed in the ABI Prism 7000 Sequence Detection System thermocycler (Applied Biosystem, Monza, Italy) under the same conditions for all the detected genes: $10 \mathrm{~min}$ of preincubation at $95^{\circ} \mathrm{C}$ followed by 40 cycles at $95^{\circ} \mathrm{C}$ for $15 \mathrm{~s}$ and $60^{\circ} \mathrm{C}$ for $1 \mathrm{~min}$. At the end of the reaction, dissociation curves were also acquired and analyzed.

Each tube for semi-quantitative PCR reaction was set up containing $4 \mu \mathrm{l}$ cDNA, $5 \mu \mathrm{l}$ of $5 \times$ buffer, $25 \mathrm{pmol}$ of forward and reverse primers (RT_SRF or RT_GAPDH), $5 \mathrm{nmol}$ of dNTP mix, and $1 \mathrm{U}$ Taq DNA polymerase (Promega, Madison, WI, USA). 
Table 1

Sequence and $T_{\mathrm{m}}$ of the primers used in this paper.

\begin{tabular}{|c|c|c|c|}
\hline Primer & Sequence $5^{\prime}-3^{\prime}$ & $T_{\mathrm{m}}\left({ }^{\circ} \mathrm{C}\right)$ & Notes \\
\hline SRF_up_Nov & CTGGAGGAAAGGTGCAA & 51.3 & 3 \\
\hline SRF_low_Nov & CTGTCTGCACTACAGAAAGA & 47.3 & 3 \\
\hline SRF_5RACE1 & TTCCAGGTTAAAGCA & 42.4 & 2 \\
\hline SRF_5RACE2 & TTGCACCTTTCCTCCAGCT & 56.7 & 2 \\
\hline SRF_5RACE3 & TTGGCTGGAAGGTTCGCT & 58 & 2 \\
\hline RACE_AAP & GGCCACGCGTCGACTAGTACGGGIIGGGIIGGGIIG & 118 & 4 \\
\hline RACE_AUAP & GGCCACGCGTCGACTAGTAC & 59.4 & 4 \\
\hline RACE_AP & GGCCACGCGTCGACTAGTACTTTTTTTTTTTTTTTTT & 71.1 & 4 \\
\hline SRF_3RACE & AATGGACTTCATTCATATTGCCC & 57.9 & 2 \\
\hline RT-SRF_up & AAAGGAATATGAGGAAAGAATTGG & 55.9 & 2 \\
\hline RT-SRF_low & TTGGCTGGAAGGTTCGCT & 58 & 2 \\
\hline RT-CYP1A1_up & ATGAACCACATCCCAGGTC & 56.7 & 1 \\
\hline RT-CYP1A1_low & TAGACATCAGTACCCTTGGG & 57.3 & 1 \\
\hline RT-GAPDH_up & ATTCCCGCCTCAACTGG & 55.2 & 1 \\
\hline RT-GAPDH_low & ATCCACGACGGACACATTTGG & 61.5 & 1 \\
\hline
\end{tabular}

Notes: (1) Primers deduced on sequences available in public data bases: Xl GAPDH U41753; XI CYP1A1 NM_001097068.

(2) Primers deduced on first obtained sequences not deposited in GeneBank.

(3) Primers deduced on orthologue sequences: scaffold_355 http://www.xenbase.org/common/; R.n. AB117752; M.m. BC080845; H.s. NM_020773.

(4) Primers included in the kits used during the experiments.

Reaction mixtures were subjected to 28 cycles, using the following parameters: denaturation at $94{ }^{\circ} \mathrm{C}$ for $30 \mathrm{~s}$, annealing, and elongation at $60^{\circ} \mathrm{C}$ for $1 \mathrm{~min}$. The PCR products were loaded on a $1 \%$ agarose gel stained with ethidium bromide and separated by electrophoresis for $30 \mathrm{~min}$ at $100 \mathrm{mV}$. The gel was acquired and the semi-quantitative analysis was carefully performed by the BIO-RAD Gel Doc 2000 connected to the software Quantity One ${ }^{\mathrm{TM}}$. That allowed to determine, in arbitrary units, the fluorescence value of the area of each considered band. After having obtained all the values, we have normalized them with those of GAPDH; then we evaluated the ratio of the treated samples compared to the control ones. In this way we have avoided the problem of differences due to template concentration in the PCR tube.

The data were statistically compared using the two tail omoschedastic Student's $t$-test. The significance level was set at $p<0.05$.

All the primers used in this work are reported in Table 1.

\subsection{Statistical analysis}

The relationships between the control and TCDD groups along with the percents of malformed larvae were investigated with the Chi-square test ( $\chi^{2}$ test).

Data from quantitative PCR were analyzed by parametric $T$-test or by nonparametric test $U$ (Mann-Whitney), considering the $\Delta C_{t}$ (Ct_SRF-2-Ct_GAPDH) values as dependent variables. The Threshold Cycle $\left(C_{t}\right)$ is the first cycle over the background.

\section{Results}

\subsection{TCDD embryotoxicity}

The TCDD embryotoxic response was evaluated in $X$. laevis larvae at the end of 5-day exposure to different TCDD concentrations, from stage 9 (late blastula) to stage 47 ( 120 h p.f.).

No significant changes were observed between the TCDDexposed and control larvae in terms of mortality even at the highest concentration $(0.62 \mu \mathrm{M})$ used (Table 2$)$. In contrast, individual larvae scored microscopically for signs of toxicity, evidenced that the percentage of malformed embryos was higher for TCDD than for untreated and DMSO control embryos even though a concentration-response was not observed (Table 2). TCDDexposed embryos were mainly affected by progressive abdominal, pericardial, and optic edema formation.

Moreover, a reduction in growth, even if not statistically significant, was evidenced by measuring the head-tail length in nonmalformed, treated larvae at the end of embriotoxicity test. Because mortality and malformation percentages were low even at $0.62 \mu \mathrm{M}$, the T.I. (LC50/EC50) could not be calculated.

The 15-day TCDD treatment, designed to monitor the toxic effects of TCDD at more advanced stages of development and to prepare samples for the subsequent molecular biology studies, produced mortality at the TCDD concentration used $(0.62 \mu \mathrm{M})$. Specifically, the low mortality seen in the 5-day toxicity test remained unchanged until day 10 and then increased exponentially starting from day 11 , reaching $100 \%$ at the end of the test. During this long term treatment the embryos underwent a visible loss of body mass comparable to a striking wasting syndrome, which is followed by eventual death, as well described in rats, mice and guinea. A similar time dependent response, but with a lower percentage of mortality, was observed in the larvae group exposed to TCDD for the first 5 days of the test and then placed in FETAX solution for the remaining 10 days (Recovery) (Fig. 1). Indeed, at the end of the recovery test, the mortality was about $65 \%$.

\subsection{Partial cloning of SRF-2}

Combining different methods, such as PCR with primers designed on orthologue sequences found in public databases, $3^{\prime}$ - and 5'-RACE and bioinformatics analysis, we obtained an $1831 \mathrm{bp}$ sequence, $1413 \mathrm{bp}$ of which are an open reading frame. This sequence has been deposited in Gen Bank with the

Table 2

TCDD embryotoxicity on Xenopus laevis (stage 47).

\begin{tabular}{|c|c|c|c|c|c|c|}
\hline & \multirow[t]{2}{*}{ Contr. } & \multirow[t]{2}{*}{ DMSO } & \multicolumn{4}{|l|}{$\operatorname{TCDD}(\mu \mathrm{M})$} \\
\hline & & & 0.125 & 0.25 & 0.5 & 0.62 \\
\hline Utilized embryos ( $n$ ) & 280 & 180 & 180 & 180 & 180 & 220 \\
\hline Dead embryos $(n)$ & 6 & 11 & 2 & 0 & 4 & 4 \\
\hline Mortality (\%) & 2.14 & 6.10 & 1.10 & 0 & 2.22 & 1.82 \\
\hline Living larvae $(n)$ & 274 & 169 & 178 & 180 & 176 & 216 \\
\hline Malformed larvae $(n)$ & 22 & 15 & 36 & 36 & 50 & 73 \\
\hline Malformed larvae (\%) & 8.03 & 8.87 & $20.22^{*}$ & $20.00^{*}$ & $28.41^{*}$ & $33.79^{*}$ \\
\hline Length $(\mathrm{mm})$ & $9.6 \pm 1.17$ & $9.47 \pm 1.23$ & $8.96 \pm 0.21$ & $9.15 \pm 1.03$ & $9.15 \pm 1.03$ & $9.29 \pm 1.09$ \\
\hline
\end{tabular}

$p<0.05$. 


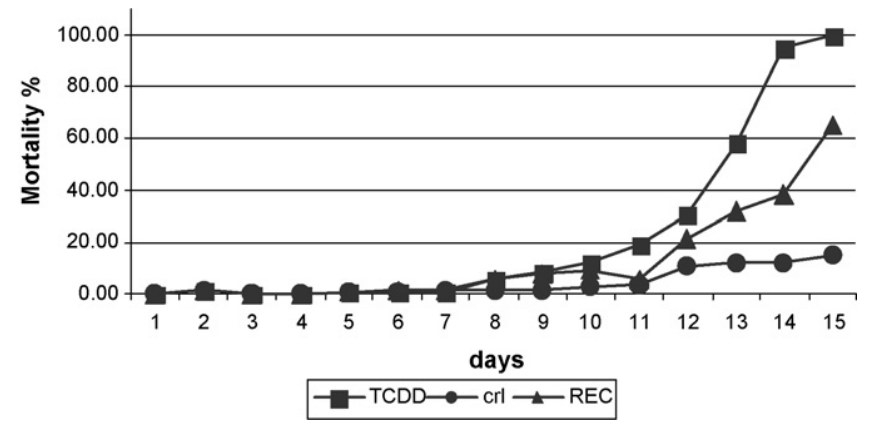

Fig. 1. Trend of mortality during long term test in Xenopus control, TCDD, and recovery embryo groups.

accession number EF635009. Nucleotide and protein Blast analysis (http://www.ncbi.nlm.nih.gov/BLAST/) confirmed that our sequence is SRF-2; it contains the classical TBC1 domain and belongs to the wide super family of KIAA genes. The identity between the Xenopus SRF-2 cDNA and that of species such as Bos taurus: XM_870617; Canis familiaris: XM_545899; Rattus norvegicus: AB117752; Mus musculus: NM_133910 and Homo sapiens: NM_020773, accounted for around 87\%.

\subsection{Semi-quantitative analysis}

The results of semi-quantitative PCR in embryos were obtained from pools derived from three different females. An example of a gel electrophoresis is reported in Fig. 2 panel A, while panel B shows the histogram of SRF-2 expression. Despite the high variability among the embryo pools, a different expression is evident during development, but not between exposed and control samples.

Fig. 3 panel A reports a gel electrophoresis of SRF-2 expression after semi-quantitative PCR in different adult tissues, while in panel $B$ we show the relative histogram. Even though the SRF-2 mRNA is mostly represented in kidney, it was distributed in all the examined tissues.

\subsection{Real-time PCR in embryos}

In panel A of Fig. 4, we reported the results, obtained by real-time PCR. The dissociation curves guarantee that no aspecific products

(A) MW

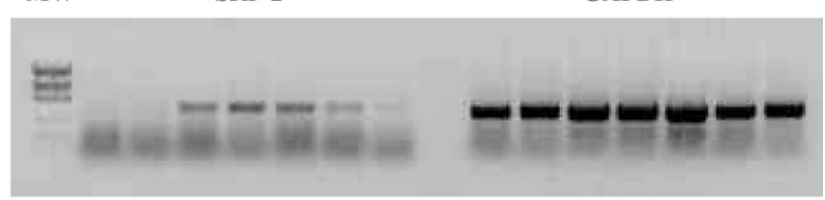

(B)

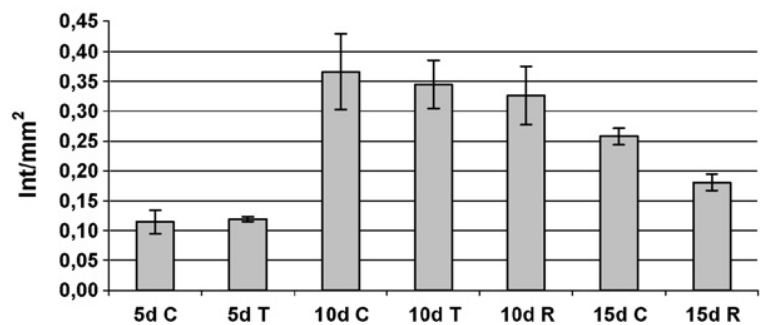

Fig. 2. Typical qualitative PCR gel (A) and relative histogram (B) of SRF-2 expression in embryos. 5 d C: day 5 p.f. control embryos; $5 d$ T: day 5 p.f. treated embryos; $10 d$ C: day 10 p.f. control embryos; 10d T: day 10 p.f. treated embryos; 10d R: embryos treated for 5 day p.f., then kept in FETAX solution until day 10 p.f.; $15 d$ C: day 15 p.f. control embryos; 15d R: embryos treated for 5 day p.f. then kept in FETAX solution until day 15 p.f.
(A)

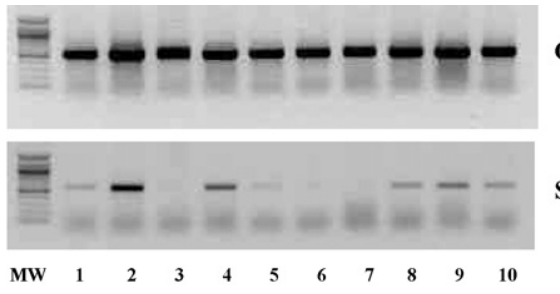

GAPDH

SRF-2

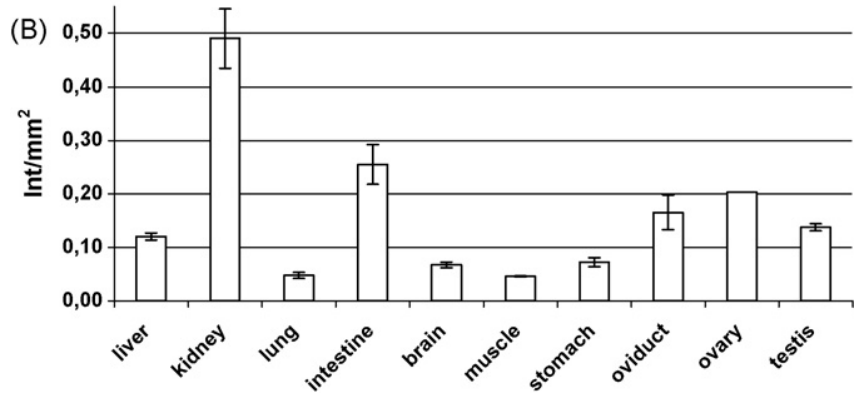

Fig. 3. Typical qualitative PCR gel (A) and relative histogram (B) of SRF-2 expression in Xenopus adult tissues. $n=3$.

were derived during the amplification; the plot of RT-PCR, reported in panel $\mathrm{B}$, indicated that, despite the wide variability among the pools, the SRF-2 mRNA is not as well represented as the housekeeping gene and that its expression does not show differences between control and exposed embryos.

\subsection{Real-time PCR in tissues}

In Fig. 5 we show the expression of mRNA SRF-2 in different adult normal tissues. Comparing these results and those obtained by the semi-quantitative analysis the trend is generally confirmed, even though, in this case, it seems that our transcript was detected more in ovary. After a single injection of TCDD $(10 \mu \mathrm{g} / \mathrm{kg}$ body weight) in adult males, the mRNA level in testis decreased although the difference is not statistically significant ( $p=0.279$; see Fig. 6 ).

\section{Discussion}

The expression of SRF-2, a gene involved in germ cell division and differentiation, has been claimed to be influenced by TCDD, a persistent environmental contaminant known to be a reproductive toxicant and endocrine disruptor in nearly all vertebrates (Sikka and Wang, 2008; King Heiden et al., 2008). Treatments with EDs influence gene expression (King Heiden et al., 2008; Iguchi et al., 2007; Moens et al., 2007; Rockett and Kim, 2005), but despite the importance of ED toxicity and the wide literature on this issue, the relationship between TCCD and SRF-2 expression is not completely clear. In a paper, Yamano et al. (2005) showed a significant decrease in SRF-2 expression in rat testis after a chronic treatment with TCDD. While it is clear that the so-called "Ah gene battery" is upregulated by TCDD treatment via the AhR signalling cascade (Pollenz et al., 1994; Nebert et al., 2000; Schultz et al., 2003; Matsumura, 2003), little is known about those genes that are downregulated such as SRF-2. Up to now the mechanism of TCDD has not been clarified; however, using a model organism characterized by low affinity of AhR toward TCDD (Lavine et al., 2005) it might be possible to hypothesize an alternative molecular mechanism of TCDD toxicity.

Taken together these results prompted us to study, in an animal model, the relationship between TCDD exposure and SRF-2 gene expression. In our experiments we found that, despite the reported $X$. laevis insensitivity to TCDD (Lavine et al., 2005), embryos exposed to $0.62 \mu \mathrm{M}$ TCDD died within 15 days. This could be due to different 
(A)

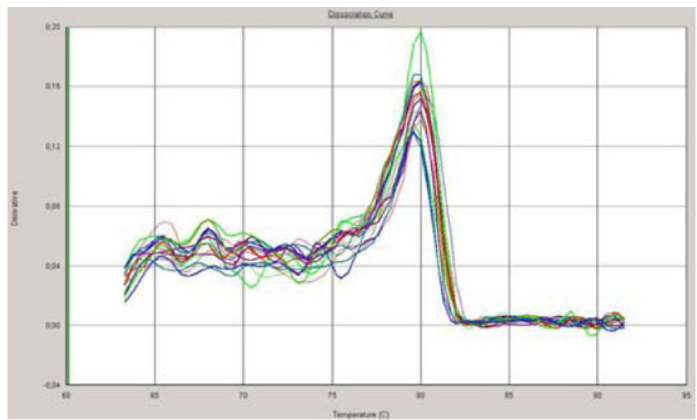

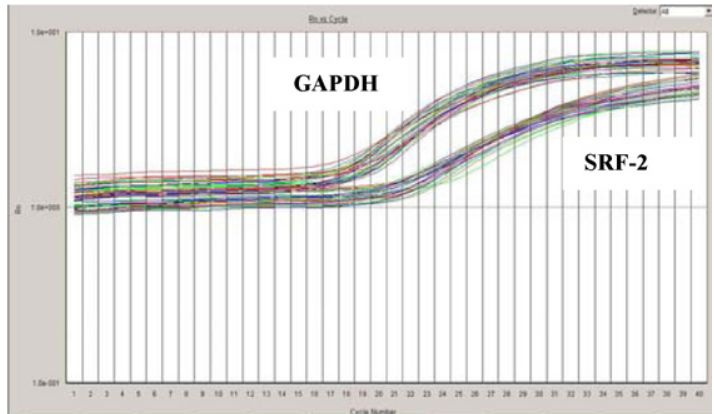

(B)

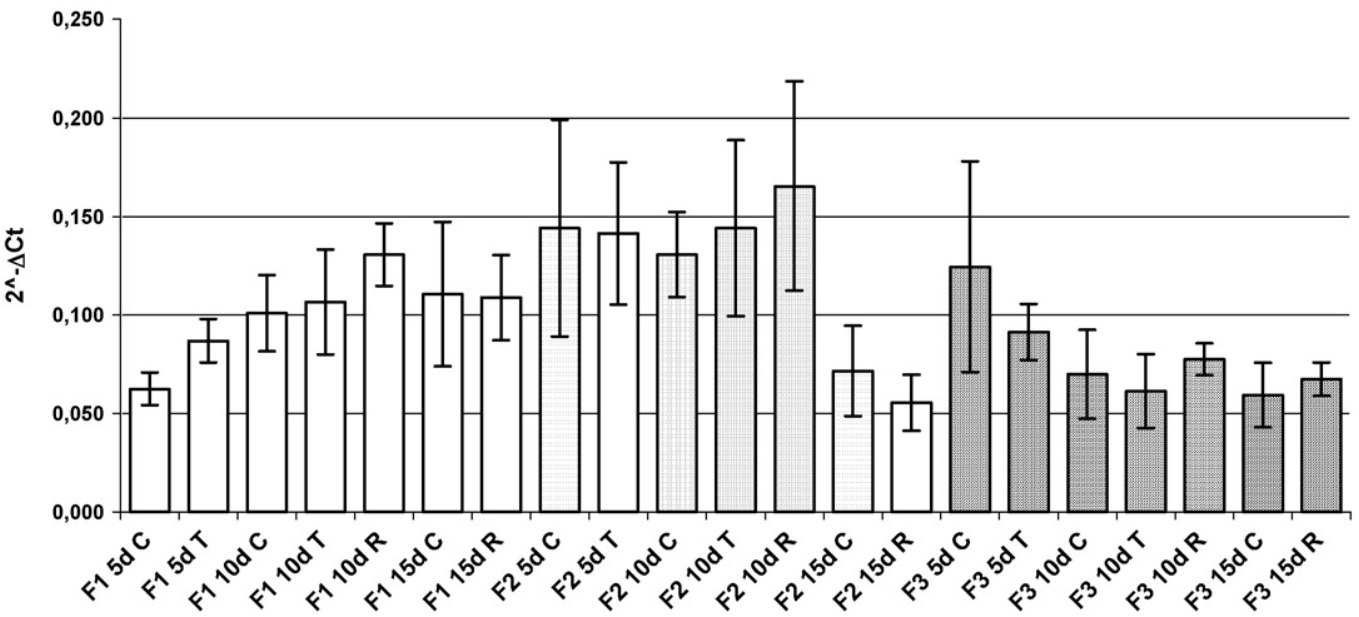

Fig. 4. (A) On the left an example of SRF-2 dissociation curves is shown, on the right, plots of GAPDH and SRF-2 expression. (B) Histograms of SRF-2 expression, obtained by real-time PCR, in the embryos derived from three different females: F1, F2 and F3. The sample groups are the same as those reported in Fig. 2.

mechanisms such as the low clearance of TCDD in X. laevis embryos during the first developmental stages (st 31-47), as reported by Philips et al. (2006), or to a decreased blood circulation that leads to a progressive edema formation, as described by Hill et al. (2004). Moreover the loss of body mass resembles the mammalian wasting syndrome, and in Xenopus it could be ascribable to apoptotic cell death in intestinal principal cells that decreases food intake (Sakamoto et al., 1999). When embryos were recovered after 5 days of TCDD exposure and placed in FETAX solution, however, they survived until the end of the experiment, showing resilience to the toxic effects of TCDD.

With the aim to evaluate SRF-2 expression, we cloned SRF-2 in X. laevis, obtaining a partial sequence that we deposited in GenBank. This allowed us to design specific primers for PCR analysis. Results

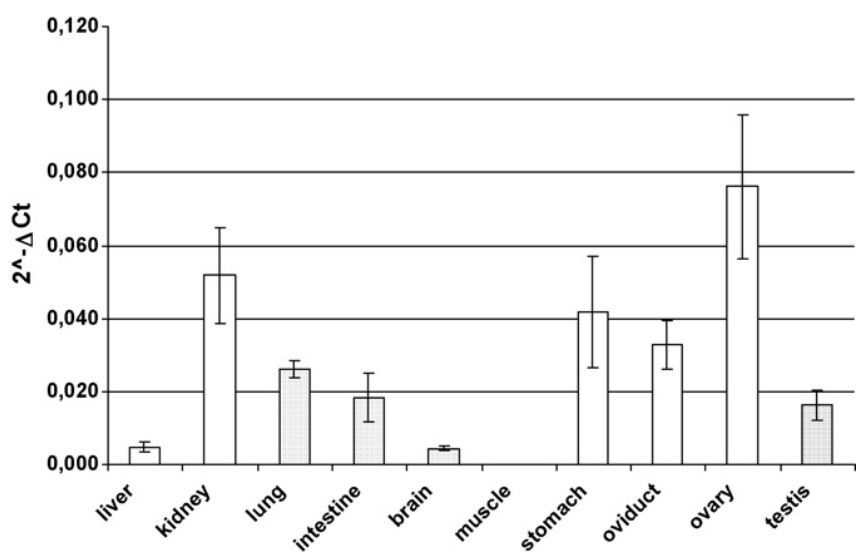

Fig. 5. Real-time PCR of SRF-2 expression in Xenopus adult tissues. $n=3$. from both qualitative and quantitative PCR showed that SRF-2 expression was very low during all the examined stages. From these data together with the great variability among the embryo pools we could not detect any significant difference between the control and exposed samples. Interesting are the data from adult control tissues: in contrast to those found by Yamano et al. (2005) in rat, SRF-2 mRNA in Xenopus tissues seems to be ubiquitous though particularly well represented in the gonads and oviduct. The reason for this discrepancy might be related to the method used for the evaluation; in fact PCR, as opposed to Northern blot, can detect few molecules of the cDNA of interest.

In this study, we also extended the analysis to the expression of SRF-2 in testis of adult X. laevis exposed to TCDD $(10 \mu \mathrm{g} / \mathrm{kg}$ body weight) in order to verify if this gene may be a promising biomarker

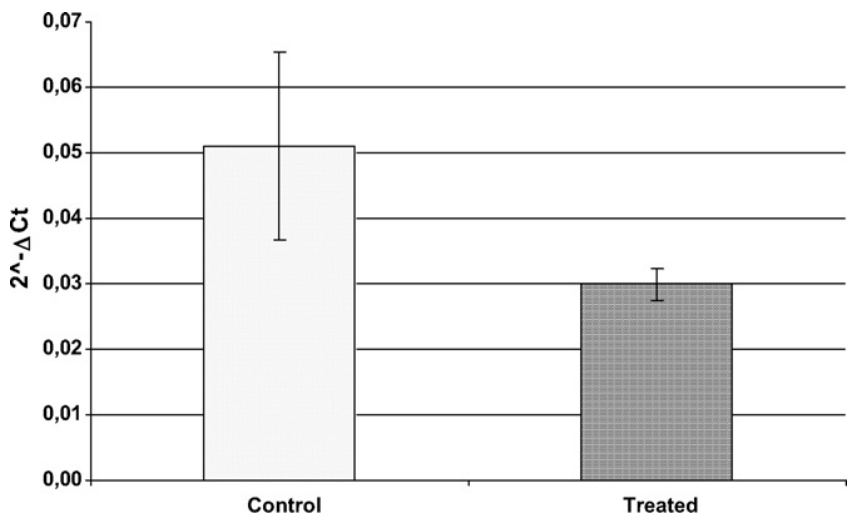

Fig. 6. Real-time PCR of SRF-2 expression in testis of control and TCDD treated adult Xenopus. $n=3$. 
to detect uncertain EDs as suggested by Yamano et al. (2005) in rat. By real-time PCR we observed only a slight decrease of SRF-2 levels in the exposed testis. This data suggests that SRF-2 cannot be proposed as a good candidate in signalling EDs exposure in all vertebrate species. Since Xenopus AhR gene is expressed already during early development, in parallel with the expression of CYP1A1 gene (Ohi et al., 2003), and the constitutive CYP1A1 protein levels are inducible by AhR agonists (Colombo et al., 1996, 2003; Dell'Orto et al., 1998), it may be argued that SRF-2 gene can not be included in the gene battery regulated by AhR signalling cascade.

Moreover, considering the multitude of AhR-regulated processes, it is difficult to exclude this underlying mechanism for TCDD toxicity and further analyses are necessary. In this regards toxicogenomics and ecotoxicogenomics studies based on microarrays focused on the search for biomarkers should be considered (Iguchi et al., 2007; Moens et al., 2007). In conclusion, the present study focused on $X$. laevis SRF-2 expression and its relationship with TCDD. First of all, we obtained a partial sequence for this gene and then we evaluated its expression in embryos and adult tissues. Although SRF-2 expression does not seem to be affected by the treatment, exposed embryos died within 15 days. In light of these results, even if Xenopus is considered relatively tolerant, TCDD seems to exert its toxicity during development by AhR mediated pathway, in the same way as in other vertebrate species.

\section{Conflict of interest statement}

The authors declare no conflict of interest for this manuscript.

\section{References}

Bernardini, G., Andrietti, F., Camantini, M., Cosson, M.P., 1988. Xenopus spermatozoon: correlation between shape and motility. Gamete Res. 20, 165-175.

Birnbaum, L.S., De Vito, M.J., 1995. Use of toxic equivalency factors for risk assessment for dioxins and related compounds. Toxicology 105, 391-401.

Choi, K.C., Jeung, E.B., 2003. The biomarker and endocrine disruptors in mammals. J. Reprod. Dev. 49, 337-345.

Colombo, A., Bonfanti, P., Cicciotelli, M., Doldi, M., Dell'Orto, N., Camatini, M., 1996 Induction of Cytochrome P4501A isoform in Xenopus laevis is a valid tool for monitoring the exposure to benzo[a]pyrene. J. Aquat. Ecosyst. Health 5, 207-211.

Colombo, A., Bonfanti, P., Orsi, F., Camatini, M., 2003. Differential modulation of and P-glycoprotein expression by aryl hydrocarbon receptor agonist and thyroid hormone in Xenopus laevis liver and intestine. Aquat. Toxicol. 63, 173-186.

Dell'Orto, N., Cantelli, D., Urani, C., 1998. Cellular targets in response to dioxin exposure. Chemosphere 37, 2809-2821.

Elskus, A.A., 2005. The implications of low-affinity AhR for TCDD insensitivity in frogs. Toxicol. Sci. 88, 1-3.
Iguchi, T., Watanabe, H., Katsu, Y., 2007. Toxicogenomics and ecotoxicogenomics for studying endocrine disruption and basic biology. Gen. Comp. Endocrinol. 153, 25-29.

Hill, A.J., Bello, S.M., Prasch, A.L., Peterson, R.E., Heideman, W., 2004. Water permeability and TCDD-induced edema in zebrafish early-life stages. Toxicol. Sci. 78, 78-87.

King Heiden, T.C., Struble, C.A., Rise, M.L., Hessner, M.J., Hutz, R.J., Carvan, M.J., 2008. Molecular targets of 2,3,7,8-tetra-chlorodibenzo-p-dioxin (TCDD) within zebrafish ovary: insights into TCDD-induced endocrine disruption and reproductive toxicity. Reprod. Toxicol. 25, 47-57.

Lavine, J.A., Rowatt, A.J., Klimova, T., Whitington, A.J., Dengler, E., Beck, C., Powell, W.H., 2005. Aryl hydrocarbon receptor in the frog Xenopus laevis: two AhR1 paralogs exhibit low affinity for 2,3,7,8-tetra-chlorodibenzo-p-dioxin (TCDD). Toxicol. Sci. 88, 60-72.

Matsumura, F., 2003. On the significance of the role of cellular stress response reactions in the toxic actions of dioxin. Comp. Biochem. Physiol. B 66, 461-465.

Moens, L.N., van der Ven, K., Van Remortel, P., Del-Favero, J., De Coen, W.M., 2007. Gene expression analysis of estrogenic compounds in the liver of common carp (Cyprinus carpio) using a custom cDNA microarray. J. Biochem. Mol. Toxicol. 21, 299-311.

Nebert, D.W., Roe, A.L., Dieter, M.Z., Solis, W.A., Yang, Y., Dalton, T.P., 2000. Role of the aromatic hydrocarbon receptor and $[\mathrm{Ah}]$ gene battery in the oxidative stress response, cell cycle control, ans apoptosis. Biochem. Pharmacol. 59, 65-85.

Nieuwkoop, P.D., Faber, J., 1994. Normal Table of Xenopus laevis (Daudin). Garland Publishing Inc., New York and London.

Ohi, H., Fujita, Y., Miyao, M., Saguchi, K., Murayama, N., Higuchi, S., 2003. Melecular cloning and expression analysis of the aryl hydrocarbon receptor of Xenopus laevis. Biochem. Biophys. Res. Commun. 307 (3), 595-599.

Philips, B.H., Susman, T.C., Powell, W.H., 2006. Developmental differences in elimination of 2,3,7,8-tetrachlorodibenzo-p-dioxin (TCDD) during Xenopus laevis development. Mar. Environ. Res. 62, S34-S37.

Pollenz, R.S., Sattler, C.A., Poland, A., 1994. The aryl hydrocarbon receptor and aryl hydrocarbon receptor nuclear traslocator protein show distinct subcellular localizations in Hepa 1c1c7 cells by immunofluorescence microscopy. Mol. Pharmacol. 45, 428-438.

Rockett, J.C., Kim, S.J., 2005. Biomarkers of reproductive toxicity. Cancer Biomark. 1, 93-108.

Sakamoto, M.K., Mima, S., Tamimura, T., 1999. Apoptosis of the intestinal principal cells of Xenopus larvae exposed to 2,3,7,8-tetrachlorodibenzo-p-dioxin. J. Environ. Pathol. Toxicol. Oncol. 18 (4), 289-295.

Semple-Rowland, S.L., Larkin, P., Bronson, J.D., Nykamp, K., Streit, W.J., Baehr, W., 1999. Characterization of the chicken GCAP gene array and analyses of GCAP1 GCAP2, and GC1 gene expression in normal and $r d$ Chicken pineal. Mol. Vis. 5 14-21.

Schultz, R., Suominen, J., Varre, T., Hakovirta, H., Parvinen, M., Toppari, J., PeltoHuikko, M., 2003. Expression of aryl hydrocarbon receptor and aryl hydrocarbon receptor nuclear traslocator messenger ribonucleic acids and proteins in rat and human testis. Endocrinology 144, 767-776.

Sikka, S.C., Wang, R., 2008. Endocrine disruptors and estrogenic effects on male reproductive axis. Asian J. Androl. 10, 134-145.

Yamano, Y., Ohyama, K., Tomoaki, S., Ritani, A., Shimada, J., Ashida, N., Yoshida, E. Ikeahara, K., Morishima, I., 2005. A novel spermatogenesis related factor-2 (SRF2) gene expression affected by TCDD treatment. Endocr. J. 52, 75-81.

Zook, D.R., Rappe, C., 1994. Environmental source, distribution, and fate of polychlorinated dibenzodioxins, dibenzofurans, and related organochlorines. In: Schecter, A. (Ed.), Dioxin and Health. Plenum Press, New York, pp. 79-113. 